\title{
Povezanost igračke pozicije na incidenciju ozljeda kod profesionalnih košarkašica u sezoni 2016./2017.
}

\author{
1 Marija Pocrnjić \\ 2 Ozren Rađenović \\ 2 Ivan Jurak \\ 1 Opća bolnica Dubrovnik \\ 2 Zdravstveno veleučilište Zagreb
}

\section{Sažetak}

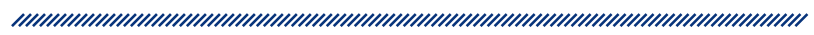

Budući da je košarka sport s puno brzih promjena, doskoka i okreta, ozljede su njezin sastavni dio te treba staviti poseban naglasak na njihovu prevenciju. Uzroci ozljeda su različiti, mogu biti unutrašnji (genski, anatomski, biomehanički, hormonalni) i vanjski (podloga, obuća), a njihov mehanizam nastanka može biti bez kontakta ili uz kontakt s igračicom ili podlogom. Kako bi se ozljede smanjile, važnu ulogu ima fizioterapeut koji bi, kao sastavni dio svake ekipe, trebao provoditi edukaciju, prevenciju i rehabilitaciju ako se ozljeda već dogodila. Prema dostupnoj literaturi, prevencija bi se trebala uklopiti u program treninga i odvijati kroz minimalno tri treninga tjedno.

Cilj ovog rada bio je utvrditi povezanost učestalosti ozljeda s obzirom na igračku poziciju u sezoni 2016./2017. Za potrebe istraživanja napravljen je upitnik s devet pitanja na koja je odgovorilo 90 košarkašica iz 12 prvoligaških klubova. Nije pronađena statistički značajna razlika između ozljeda gležnja, koljena i Ahilove tetive s obzirom na igračku poziciju.
Ključne riječi: ženska košarka, najčešće ozljede, uzroci ozljeda, fizioterapija, prevencija

Datum primitka: 03.03.2021.

Datum prihvaćanja: 15.04.2021.

https://doi.org/10.24141/1/7/2/6

Adresa za dopisivanje:

Ozren Rađenović

A: Zdravstveno veleučilište Zagreb, Mlinarska 38

E-pošta: ozren.radenovic@zvu.hr

T: +385914595937 


\section{Uvod}

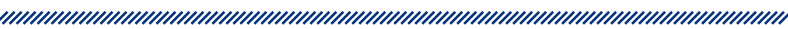

U današnjem svijetu sport je jedan od najpoznatijih načina kojima se promovira zdravlje. Velik broj dokaza podupire činjenicu da su benefiti zdravlja povezani s participacijom u sportskim aktivnostima, ${ }^{1}$ ali s druge strane istraživanja pokazuju da je preveliko opterećenje sportaša, pogotovo u natjecateljskom sportu, povezano $\mathrm{s}$ povećanim rizikom nastajanja mišićno-koštanih ozljeda. $^{2}$

Košarka se smatra jednim od najpopularnijih sportova širom svijeta. ${ }^{3}$ To je sport koji se igra između dvije ekipe s pet igrača na svakoj strani. Klasificira se kao sport srednjeg intenziteta koji kombinira anaerobnu i aerobnu aktivnost. Poznato je da anaerobna kontribucija važna za taktičke i tehničke radnje, dok trajanje košarkaške igre (40 - $48 \mathrm{~min}$ ) zahtijeva visoku razinu aerobnog metabolizma kako bi se poboljšala resinteza kreatin fosfata, uklanjanje laktata iz aktivnog mišića i uklanjanje nakupljenoga intracelularnog anorganskog fosfata. ${ }^{4} \mathrm{Ti}-$ jekom sezone, u kojoj trenažni proces mora biti sastavljen od tri komponente: uvodnog perioda, natjecanja te prijelaznog perioda, ${ }^{5}$ i košarkaši i košarkašice svakodnevno treniraju, čak i po dva puta dnevno, te sudjeluju u europskim i svjetskim natjecanjima te Olimpijskim igrama.

lako se autori ne slažu oko toga je li košarka beskontaktni sport ${ }^{6}$ ili sport s limitiranim kontaktom, ${ }^{7}$ to je agilan sport, sport s mnogo brzih kretnji, skokova, promjena smjera i rotacija te se zato ozljede često događaju, pogotovo kod ženske populacije. ${ }^{6}$ Deitch i suradnici u svojem su istraživanju uspoređivali učestalost ozljeda u muškoj i ženskoj košarci te su dokazali da je ženska populacija imala čak 60 \% više ozljeda od muške. ${ }^{8}$ Zbog velike prevalencije ozljeda, svaki klub bi trebao imati fizioterapeuta čija bi zadaća bila edukacija sportaša o ozljedama, o provođenju prevencije i rehabilitacije ako se ozljeda već dogodila. ${ }^{9}$

Ozljede donjih ekstremiteta predstavljaju veliki problem sportašima diljem svijeta. ${ }^{10}$ Muškarci i žene imaju drukčiju anatomiju tijela, pa se tako i ozljede koje zadobivaju znatno razlikuju. Zbog razlika u obliku zdjelice, žene doskaču drukčije nego muškarci. Dok muškarci doskaču u flektiranom položaju da bi zaštitili koljena, žene imaju tendenciju doskakati u nepravilan X-položaj. ${ }^{11}$ Veća incidencija ozljeda zabilježena je i zbog labavosti i fleksibilnosti zglobova, ${ }^{12}$ nejednake snage i aktivacije mišića prednje i stražnje natkoljenične muskulature gdje se snaga kvadricepsa pokazala dvostruko većom od snage hamstringsa nakon menarhe pri manevrima doskoka, ${ }^{13}$ također zbog recurvatuma koljenog zgloba, povećanog stražnjeg nagiba tibije, deficita propriocepcije cora ili smanjene neuromuskularne kontrole. ${ }^{11} \mathrm{Ze}$ lisko i sur. u svojem istraživanju navode da su razlike u stopi ozljeda između muškarca i žena pokazale da ženska populacija zadobije $60 \%$ više ozljeda nego muška. ${ }^{14}$

Trima primarnim mehanizmima ozljeda u košarci smatraju se: kontaktni s drugim igračem, kontaktni s drugom površinom (podom, loptom) i beskontaktni. ${ }^{15} \mathrm{Be}-$ skontaktni se dijele na: ozljede u doskoku, okretanju oko stojne noge s loptom ili bez nje (pivotiranje) te na različite oblike kretanja po terenu. Dva specifična mehanizma nastanka ozljede jesu doskok na podlogu ili na nečiju nogu, a čine $43 \%$ svih ozljeda u košarci, dok kolizija s drugim igračem čini $21 \% .{ }^{16}$ Kao pokazatelj učestalosti ozljeda može se uvrstiti i rizik od ozljeda po satu izloženosti. Definira se kao broj ozljeda podijeljen s brojem sati u kojima je igrač izložen ozljedi. S prosječnih 11 igrača u jednom timu, rizik ozljede procjenjuje se na $0,4 \%$ po satu izloženosti.

Međutim, treba podsjetiti na to da se u ovom izračunu pretpostavlja da je izloženost ozljedama jednaka kod svakog igrača tako da stvarna izloženost ozljedi može biti znatno veća za igrače koji više sudjeluju u igri ili manja za one koji sjede na klupi. ${ }^{17}$

\section{Metodologija istraživanja}

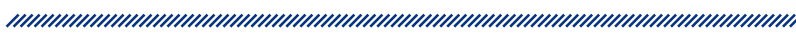

\section{Cilj istraživanja}

Cilj je ovog rada prikazati učestalost različitih ozljeda u ženskoj profesionalnoj košarci u sezoni 2016./2017. Formulirana je nul hipoteza:

- H0: Pozicija igračica nije povezana s učestalošću ozljeda koljena, gležnja i Ahilove tetive

\subsection{Materijali i metode}

U svrhu ovog istraživanja provedena je anketa u kojoj je sudjelovalo 90 košarkašica iz 12 klubova u Hrvatskoj (80\% ciljane populacije). Dob ispitanica kretala se od 
15 do 34 godine, a sve su bile članice seniorskih sastava svojih klubova. Upitnik je napravljen za potrebe izrade ovog rada i sastoji se od 14 pitanja:

1. Ime i prezime

2. Godine

3. Broj treninga tjedno

4. Koliko godina trenirate?

5. Koju poziciju igrate?

6. Jeste li bili ozlijeđeni u sezoni 2016./2017.?

7. Ako je odgovor da, koja je struktura bila zahvaćena?

8. Jeste li ikada bili ozlijeđeni?

9. Ako je odgovor da, koja je struktura bila zahvaćena? Ozljede su klasificirane topografski - gležanj, koljeno ili Ahilova tetiva te nije uziman u obzir tip ozljede. Podaci su analizirani s pomoću Fisherova egzaktnog testa u računalnom programu R (ver. 4.0.2.).

\section{Rezultati}

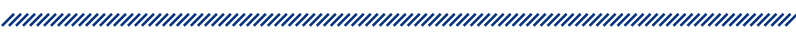

U tablici 1 prikazana je prosječna $(\bar{x})$ dob igračica, broj godina treniranja i broj treninga tjedno te standardna devijacija (SD) navedenih parametara.

\begin{tabular}{|c|c|c|}
\hline \multicolumn{3}{|c|}{ Tablica 1. Demografske karakteristike } \\
uzorka \\
\hline & $\bar{x}$ & SD \\
\hline Dob igračica & 20,93 & 4,14 \\
\hline Broj godina treniranja & 9,86 & 4,27 \\
\hline Broj treninga tjedno & 6,18 & 2,06 \\
\hline Legenda: $\bar{x}$ - srednja vrijednost; SD - standardna devijacija \\
\hline
\end{tabular}

Budući da je riječ o profesionalnim igračicama, ne iznenađuje činjenica da se u prosjeku igračice bave košarkom pola svoje životne dobi te da treniraju oko šest puta u tjednu. Slika 1 prikazuje incidenciju ozljeda s obzirom na topografsku poziciju igračica.

Fisherov egzaktni test nije pokazao statistički značajnu povezanost $(p=0,52)$ između topografije ozljede i pozicije igračica.

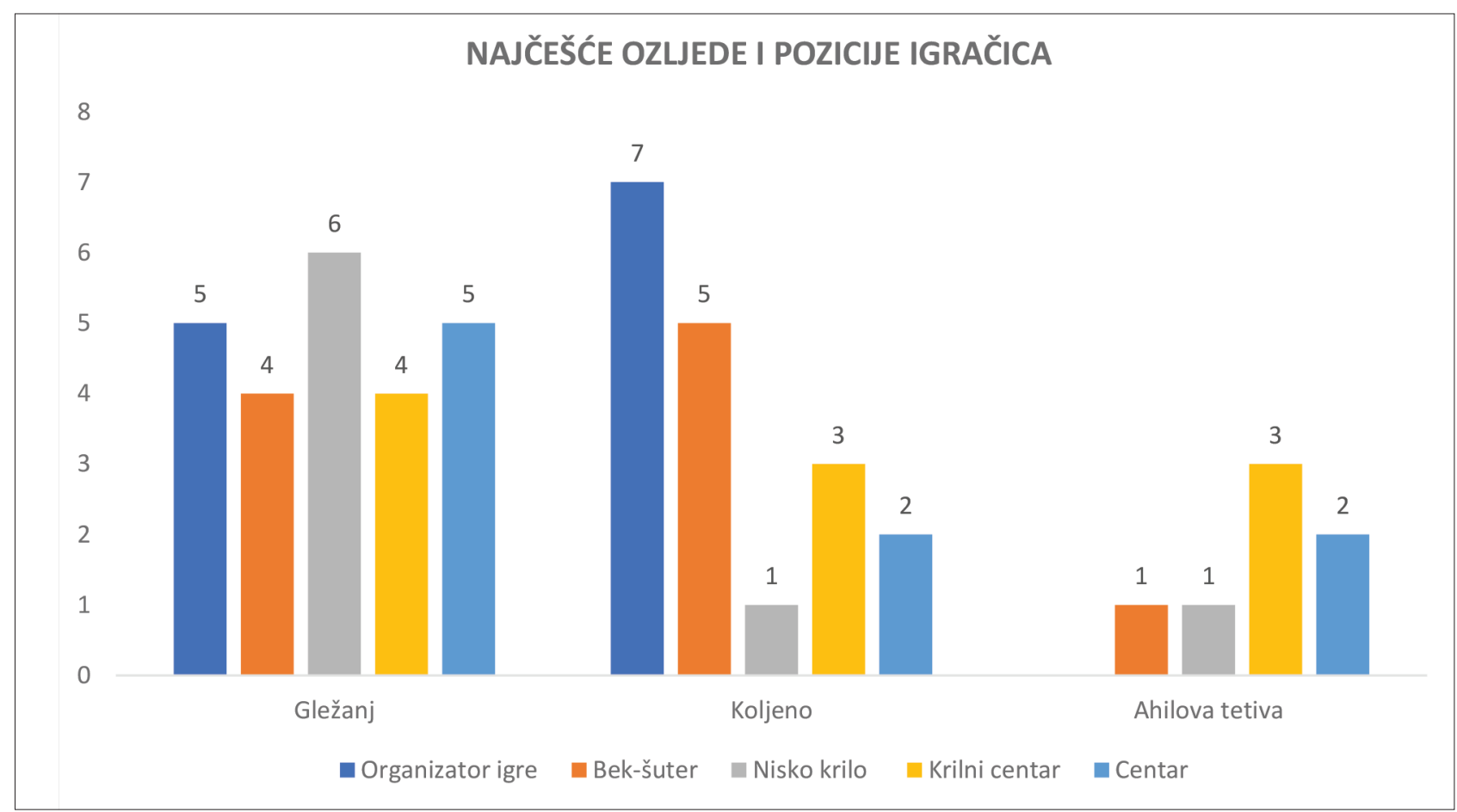

Slika 1. Prikaz ozljeda gležnja, koljena i Ahilove tetive s obzirom na pozicije igračica 


\section{Rasprava}

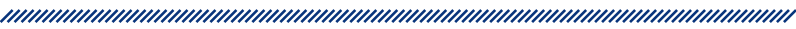

Tijekom jednog godišnjeg trenažnog ciklusa (sezona 2016./2017.) 90 hrvatskih profesionalnih košarkašica zadobilo je ukupno 57 ozljeda. Ozljede gležnja zauzimaju najveći broj ozljeda, ali s obzirom na to da je samo jedna od tih ozljeda zahtijevala operacijsko liječenje, igračice s takvim ozljedama i najbrže su se vraćale na teren. Sljedeća po učestalosti bila je ozljeda prednjega ukriženog ligamenta, koja zahtijeva najduže izbivanje i najdužu rehabilitaciju (6 do 12 mjeseci).

U ovom je ispitivanju utvrđeno kako igračka pozicija nema značajne povezanosti s lokalitetom pretrpljene ozljede. Sličan zaključak donijeli su McKay i suradnici, utvrdivši da pozicija igračica nema utjecaj na nastajanje ozljede gležnja. ${ }^{16}$ S druge strane, ovo je istraživanje kontradiktorno istraživanju provedenom među grčkim profesionalnim košarkašicama, gdje je utvrđeno da najviše ozljeda gležnja zadobivaju centri. ${ }^{17}$ Nadalje, Meeuwisse i suradnici potvrđuju hipotezu da se ozljeda Ahilove tetive događa više kod igračica na poziciji centra, ali s druge strane odbacuju hipotezu da se ozljede koljena događaju više organizatorima igre i bek-šuterima. ${ }^{18}$

Unatoč tome što je istraživanju pristupilo 80 \% ciljane populacije, nedostatak je maleni uzorak i maleni vremenski raspon koji bi omogućio većinu razinu generalizacije ovih rezultata na populaciju košarkašica.

\section{Zaključak}

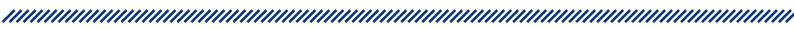

Ozljede donjih ekstremiteta čine $90 \%$ ozljeda u sportu, a njihova se učestalost povećava u sportovima s brzim promjenama smjera i skakačkim sportovima kao što je košarka. Ženska populacija ima znatno veću prevalenciju ozljeda pa bi se uz iskorištavanje sporta kao najboljeg načina promocije zdravlja trebalo mnogo više posvetiti negativnim stranama i posljedicama bavljenja sportom. Bez obzira na to što će se ozljede uvijek događati, prevencija je važan dio fizioterapije koji pomaže smanjiti njihovu učestalost te osigurati stabilnost i fleksibilnost zgloba te jakost muskulature koja ga okružuje.

Upravo je zbog toga važna edukacija fizioterapeuta kako bi se incidencija ozljeda smanjila na najmanju mo- guću razinu. Fizioterapeut bi trebao biti sastavni dio svake ekipe, bez obzira na to je li ekipa profesionalna ili amaterska, te pomoći sportašicama u boljoj pripremi za treninge i natjecanja. Ako se ozljeda dogodi, vrlo je važan proces rehabilitacije i motivacija sportašice za oporavak i povratak sportu te kvalitetan individualni rad s fizioterapeutom.

\section{Referencije}

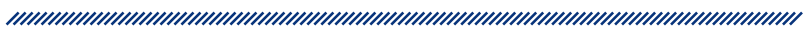

1. Haskell WL, Lee I-M, Pate RR, et al. Physical activity and public health: updated recommendation for adults from the American College of Sports Medicine and the American Heart Association. Med Sci Sports Exerc. 2007; 39: 1423-1434.

2. Alonso JM, Junge $A$, Renström $P$, et al. Sports injuries surveillance during the 2007 IAAF World Athletics Championships. Clin J Sport Med. 2009; 19: 26-32.

3. Lidor R, Blumenstein B, Tenenbaum G. Psychological Aspects of Training in European Basketball: Conceptualization, Periodization, and Planning. Sport Psychologist. 2007; 21: 353-367.

4. Castagna A, Garofalo R, Cesari E, et al. Posterior superior internal impingement: an evidence-based review [corrected]. Br J Sports Med. 2010; 44: 382-388.

5. Ziv G, Lidor R. Physical attributes, physiological characteristics, on-court performances and nutritional strategies of female and male basketball players. Sports Med. 2009; 39: 547-568.

6. McInnes SE, Carlson JS, Jones CJ, et al. The physiological load imposed on basketball players during competition. J Sports Sci. 1995; 13: 387-397.

7. Hootman JM, Dick R, Agel J. Epidemiology of Collegiate Injuries for 15 Sports: Summary and Recommendations for Injury Prevention Initiatives. J Athl Train. 2007; 42: 311-319.

8. Deitch JR, Starkey C, Walters SL, et al. Injury risk in professional basketball players: a comparison of Women's National Basketball Association and National Basketball Association athletes. Am J Sports Med. 2006; 34: 10771083.

9. Peterson L, Renstrom PAFH. Sports Injuries: Prevention, Treatment and Rehabilitation, $4^{\text {th }}$ edition. Boca Raton: Routledge, 2016.

10. Walbright PD, Walbright $\mathrm{N}$, Ojha $\mathrm{H}$, et al. Validity of functional screening tests to predict lost-time lower quarter injury in a cohort of female collegiate athletes. Int J Sports Phys Ther. 2017; 12: 948-959.

11. Nakase J, Kitaoka K, Shima Y, et al. Risk factors for noncontact anterior cruciate ligament injury in female high 
school basketball and handball players: A prospective 3-year cohort study. Asia-Pacific Journal of Sports Medicine, Arthroscopy, Rehabilitation and Technology. 2020; 22: 34-38.

12. Mccarthy M, Voos J, Nguyen J, et al. Injury Profile in Elite Female Basketball Athletes at the Women's National Basketball Association Combine. The American journal of sports medicine; 41. Epub ahead of print 1 February 2013. DOI: $10.1177 / 0363546512474223$.

13. Ahmad CS, Clark AM, Heilmann N, et al. Effect of Gender and Maturity on Quadriceps-to-Hamstring Strength Ratio and Anterior Cruciate Ligament Laxity. Am J Sports Med. 2006; 34: 370-374.

14. Zelisko JA, Noble HB, Porter M. A comparison of men's and women's professional basketball injuries. Am J Sports Med. 1982; 10: 297-299.
15. Burnham BR, Copley GB, Shim MJ, et al. Mechanisms of basketball injuries reported to the HQ Air Force Safety Center a 10-year descriptive study, 1993-2002. Am J Prev Med. 2010; 38: S134-140.

16. McKay G, Goldie P, Payne W, et al. Ankle injuries in basketball: injury rate and risk factors. $\mathrm{Br} J$ Sports Med. 2001; 35: 103-108.

17. Mihata LCS, Beutler AI, Boden BP. Comparing the incidence of anterior cruciate ligament injury in collegiate lacrosse, soccer, and basketball players: implications for anterior cruciate ligament mechanism and prevention. Am J Sports Med. 2006; 34: 899-904.

18. Meeuwisse WH, Sellmer R, Hagel BE. Rates and risks of injury during intercollegiate basketball. Am J Sports Med. 2003; 31: 379-385. 
CORRELATION BETWEEN THE PLAYER POSITION AND THE INCIDENCE OF INJURIES IN FEMALE PROFESSIONAL BASKETBALL PLAYERS IN THE 2016/2017 SEASON

1 Marija Pocrnjić

2 Ozren Rađenović

2 Ivan Jurak

1 General hospital Dubrovnik

2 University of Applied Helath Sciences
Keywords: women basketball, most frequent injuries, causes of injuries, physiotherapy, prevention

\section{Summary}

Basketball is a sport with a lot of quick movements, landings and turns. Injuries are an integral part of it and special emphasis should be placed on their prevention. Various factors influence the probability of an injury. The factors can be internal (genetic, anatomical, biomechanical, hormonal) and external (surface, footwear), and the mechanism of injury can be in contact with the player or surface or without any contact. In order to reduce injuries, an important role is played by a physiotherapist who, as an integral part of each team, should conduct education, prevention and rehabilitation. According to the available literature, prevention should be included into the training program and take place during a minimum of three workouts per week. The aim of this study was to determine the correlation between the frequency of injuries with respect to the player position in the 2016/2017 season. A questionnaire with 9 questions was designed and given to $90 \mathrm{fe-}$ male basketball players from 12 first league teams. No statistically significant difference was found between ankle, knee and Achilles tendon injuries with respect to the player position. 